\title{
ERRATUM
}

\section{The analysis of genetic recombination on the polaron hybrid DNA model}

\author{
BY H. L. K. WHITEHOUSE AND P. J. HASTINGS
}

Genet. Res. (1965), 6, 27-92

On p. 58, Table 7, in the column headed $y_{p c}$, the entries relating to genotypes nos. 17 and 18, 19 and 21, 20 and 22 , and 27 and 28 should be transposed within each pair, so that the column reads: $17, \frac{1}{8} ; 18, \ldots ; 19, \frac{1}{8} * ; 20, \frac{1}{8} ; 21, \ldots ; 22, \ldots ; 23, \frac{1}{16} *$; $24, \frac{1}{16} ; 25, \frac{1}{16} * 26, \frac{1}{16} ; 27, \frac{1}{8} * 28,-; 29, \frac{1}{16} ; 30, \frac{1}{16} ; 31, \frac{1}{16} * ; 32, \frac{1}{16}$. Total (wildtypes), $\frac{7}{16} *$. 